\title{
En torno a las cenizas volantes en los cementos y en los hormigones, a la luz de un trabajo presentado en el $7 .^{\circ}$ Congreso Internacional de la Química de los Cementos
}

Prof. Dr. JOSE CALLEJA - IETCC

\section{$R E S U M E N$}

Al hilo de unos comentarios hechos recientemente por el conocido y documentado autor A. VIRELLA $B L O D A$ en un amplio $y$ detallado informe sobre el mencionado Congreso, en la Revista CEMENTO-HORMIGON (véase referencias) con relación a la Mesa Redonda del tema IV del mismo, conrerniente a PUZOLANAS Y CENIZAS VOLANTES, y en particular a una comunicación presentada en dicho tema, el firmante de este trabajo hace unas consideraciones personales acerca de las puzolanas en general y de las cenizas volantes en particular, en aspectos generales, $y$ más especificamente en los relativos a la corrosión de las armaduras, objeto principal de la citada comunicación.

\author{
$S U M M A R Y$
}

With reference to some comments recently made by the well known and informed author A. VIRELLA BLODA in a wide and detailed report on the Congress referred to, published in the Technical Review CEMENTO-HORMIGON, concerning the Round Table of Theme IV: POZZOLANAS AND FLY-ASHES and particularly to a paper presented under this item, the author of this work makes some personal considerations on pozzolanas in general and particularly on fly-ashes, dealing with general aspects of them, and more specifically with those related to reinforcement corrosion, which is the main object of the mentioned paper.

Al pasar revista al extenso y analítico, si que también original informe de Alberto VIRELLA BLODA sobre el 7. CONGRESO INTERNACIONAL DE LA QUIMICA DE LOS CEMENTOS (París, Juilio 1980), publicado en la Revista Técnica CEMENTO-HORMIGON (1) (2) (3) (4) (5), parece destacar, dentro de la consideración del tema IV: PUZOLANAS Y CENIZAS VOLANTES (5) y de la Mesa Redonda del mismo, y en el apartado 11 relativo a DURABILIDAD, el aspecto diferencial entre los cementos puzolánicos - se entiende que conteniendo puzolanas naturales-, y los cementos con cenizas volantes, a los que no se les llama puzolánicos - pero en todo caso conteniendo puzolanas "artificiales"-, tal vez para mejor distinguir unos de otros.

Si se toman en consideración los criterios, opiniones e ideas que, según VIRELLA, manifestaron R. MAGNAN, K. TAKEMOTO, P. LONGUET, F. MASSAZZA y R. TSUKAYAMA, únicos participantes de la Mesa Redonda citados por VIRELLA, hay que empezar por decir que, efectivamente, a juicio del autor de este trabajo, MAGNAN está en lo cierto en las dos consideraciones que hace. En cuanto a la primera, es decir, a la dualidad evidente entre la resistencia mecánica y la tresistencia química, resulta innegable que ambas resistencias son distintas, pero siempre interdependientes, directa o indirectamente, en paralelo o en contracorriente. 
En efecto: por una parte, a mayor resistencia mecánica del hormigón a cualquier edad, suele corresponder mayor resistencia química del mismo a igualdad de toda otra circunstacia, ya que el efecto negativo final de todo ataque químico es la ruina de la resistencia mecánica y, cuanto mayor sea ésta, mayor será la capacidad de aguante del material. Y esto sin contar con otros factores físicos que suelen acompañar a las altas resistencias mecánicas, como son una gran compacidad e impenetrabilidad, las cuales contribuyen de por sí a una mayor resistencia química, que a su vez salvaguarda la resistencia mecánica.

Pero, por otra parte, los constituyentes del clínker que más contribuyen a las mayores resistencias mecánicas a corto y/o a largo plazo, y principalmente el $\mathrm{C}_{3} \mathrm{~S}$ y el $\mathrm{C}_{3} \mathrm{~A}$, son los que más vulnerable hacen a la pasta cementante frente a prácticamente todos los

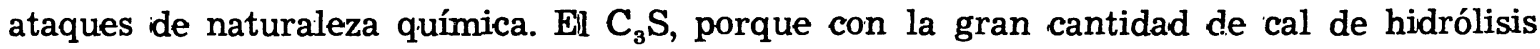
que libera hace débil a la pasta frente a la lixiviación por aguas puras y al ataque por aguas ácidas y carbónicas agresivas; el $\mathrm{C}_{3} \mathrm{~A}$, por su sensibilidad ạl ataque por sulfatos en general y por agua de mar. Así, pues, cementos ricos en estos constituyentes, que darían resistencias mecánicas altas a toda edad, darían también pastas hidratadas más débiles frente a eventuales ataques de la naturaleza de los señalados. De aquí que los cemen tos portland sin constituyentes secundarios activos - adiciones activas - no sean los más aptos para resistir esos tipos de ataques, y sí lo sean, en cambio, los cementos que en una $\mathrm{u}$ otra proporción contienen puzolanas (naturales o artificiales $-\mathrm{y}$ entre estas últimas las cenizas volantes idóneas-), o escorias siderúrgicas adecuadas; máxime cuando con dichos cementos se logran resistencias mecánicas suficientes a los plazos requeridos. Por un lado, los constituyentes secundarios activos actúan de diluyentes del clínker y de sus componentes $-\mathrm{y}$ en particular de los vulnerables por los ataques-, con lo cual se mejora la resistencia química, a costa de sacrificar una pequeña parte de la resistencia mecánica, sobre todo a corto plazo; y, por otro lado, la resistencia mecánica a plazos medio y largo de los cementos con constituyentes secundarios llega a ser más que suficiente, merced a las acciones de tipo puzolánico, de desarrollo lento pero continuo, y/o a la hidraulicidad latente de dichos constituyentes. En definitiva, no basta tener un hormigón de alta resistencia mecánica temprana, si ésta no se puede sostener a lo largo del tiempo frente a las agresiones químicas. Es preferible tener hormigones de resistencia mecánica menor, aunque suficiente a corto plazo, la cual se pueda mantener e incrementar a plazos más largos, con aumento simultáneo de las condiciones favorables para una buena resistencia química. Este es el principio fundamental y la razón de ser de los cementos puzolánicos y siderúrgicos, de tecnología de fabricación y de utilización consagradas y, por otra parte, bien conocidos y experimentados durante muchos años en diversos países; por ejemplo, los primeros en Italia y los segundos en Alemania.

Por todo ello es válido el criterio de MAGNAN expuesto por VIRELLA, en el sentido de que es conveniente y necesario ensayar las resistencias mecánica y química, pero en el bien entendido de que la resistencia mecánica que se debe ensayar - y exigir- en casos de ataques químicos previsibles, es la de los cementos que por su naturaleza sean resistentes a cada tipo de ataque, y no la de los que no lo sean. En conclusión: frente a posibles agresiones de tipo químico, lo primero es elegir el cemento idóneo, específicamente resistente a ellas; lo segundo, cerciorarse de que las resistencias mecánicas que da para el tipo de hormigón y obra, y a los plazos fijados, son suficientes; y lo tercero, corroborar mediante ensayos que la resistencia química "nominal" del cemento es también "efectiva". Y lo cuarto, que podría ser primerísimo, que la tecnología, esto es, la ejecución del hormigón, sea la adecuada. Es decir, hay que partir de la base de que cementos que por razones de composición y de constitución deben ser más resistentes que otros frente a un determinado tipo de ataque químico, a igualdad de todo lo demás, en la generalidad de los casos lo son. Por ejemplo, no se puede dudar de que, en principio, un cemento puzolánico o siderúrgico hecho con un clínker bajo en $\mathrm{C}_{3} \mathrm{~A}$ resiste mejor que un portland los ataques por aguas puras, ácidas, sulfatadas y de mar. 
Por eso también, la evaluación de las puzolanas no se debe hacer sobre la base de los resultados de un solo ensayo fundamentado en una sola característica o parámetro del material, pues tal método sólo serviría, y con reservas, para enjuiciar los materiales de una misma familia - naturaleza, procedencia, génesis, composición y constitución- (6) (7).

En cuanto a los ensayos de puzolanas con cal - se entiende que para determinar la acción puzolánica en el tiempo, por medios mecánicos de rotura de probetas-, de acuerdo con MAGNAN no son nada realistas, pues hoy día no se emplean las puzolanas con cal, como en tiempos de los romanos, sino con cemento. Las resistencias dependen de la naturaleza del clínker y de la puzolana, de la proporción de mezcla y de la finura del cemento resultante (8). El ensayo con cal puede servir para comparar puzolanas entre sí "en abstracto". Pero "en concreto" puede ocurrir - y ocurre- que para un clínker dado o una puzolana dada no todas las puzolanas o todos los clínkeres se comportan igual, variando según unos y otras las proporciones de mezcla y las finuras óptimas, y eso hay que determinarlo experimentalmente de forma directa, con cada par de materiales clínker y puzolana, en cada caso.

En este sentido está de acuerdo la respuesta de MAGNAN a la pregunta de G. K. MOIR en la Mesa Redonda del Tema IV del mencionado Congreso (7), en cuanto a que los ensayos mecánicos para la evaluación de las puzolanas se deben hacer en condiciones reales - con clínker mejor que con cal-, y teniendo en cuenta que es preciso distinguir dos aspectos diferentes: uno, la velocidad de reacción química de los materiales con el agua, la cual es tanto mayor cuanto mayor es la finura de éstos, sin cortapisas; y otro, la velocidad de endurecimiento o de desarrollo de las resistencias, la cual también es tanto mayor cuanto mayor es la finura, pero con la cortapisa de que la mayor finura exige en general una mayor relación agua/cemento, la cual perjudica a las resistencias, y en particular a las de corta edad.

En este orden de ideas, decir -como según VIRELLA dice TAKEMOTO- que los cemen. tos puzolánicos (se entiende que con puzolanas naturales, aunque tal extremo no se especifica) responden a las condiciones de durabilidad (también sin especificar), a la resistencia a los álcalis y a los ataques químicos (asimismo sin especificación alguna), mucho mejor que los cementos de cenizas volantes (igualmente considerados en bloque), es mucho decir, pues ello dependerá en cada caso de qué cementos se trate (esto es, de qué clínkeres y qué materiales de adición, y en qué proporciones y con qué finuras), de qué tipos de ataque se produzcan, y en qué condiciones se den éstos. En este sentido las generalizaciones y las extrapolaciones pueden ser viciosas.

En lo que respecta a la inexistencia de procedimientos normalizados o universales reconocidos para medir y evaluar la durabilidad de los cementos con adiciones, que VIRELLA pone en boca de LONGUET con el apoyo de TAKEMOTO y de MASSAZZA, hay que decir que, si ello es así, no lo es sólo para los cementos con adiciones, sino para todos los cementos en general. Pero parece ser, visto de otro modo, que no es del todo así, puesto que normalizados o no, universalmente reconocidos o no, existen desde antiguo métodos, al menos para determinar de alguna manera la resistencia frente al ataque de los sulfatos en general o del cálcico en particular: LE CHATELIER-ANSTETT-BLONDIAU, WITTEKINDT, KOCH \& STEINEGGER, MERRIMAN-GARCIA DE PAREDES, ASTM, APCM, CERILH, etc., los cuales han sido puestos en práctica en estudios comparativos hechos en común por organismos internacionales, y precisamente para comparar comportamientos de cementos de diferentes tipos: portland, siderúrgicos y puzolánicos, entre otros.

Bien es verdad que los resultados de unos y de otros métodos entre los citados, no siempre son concordantes, ni entre sí, ni con el comportamiento real previsible de los cemen- 
tos en la práctica (9) (10), dado lo que cabe esperar de la composición y de la constitución de los mismos. Pero también es cierto que, al menos uno de tales métodos, el de KOCH \& STEINEGGER, que por otra parte es el más "cuantitativo", es el que juzga y evalúa a los distintos tipos de cemento más en consonancia con su presunto comportamiento real, en función de su naturaleza y características.

Por otra parte, los ensayos a largo plazo referidos por TSUKAYAMA y sus colaboradores, según VIRELLA, y llevados a cabo a efectos comparativos para determinar la resistencia a la corrosión - de armaduras- de hormigones armados hechos a base de cementos de cenizas volantes, no permiten, por razones obvias, generalizar las conclusiones a otras cenizas que las estudiadas por los autores -éstos ya indican que no tuvieron en cuenta las de lignitos-, y mucho menos a otras puzolanas.

Pero el trabajo presentado por TSUKAYAMA, ABE y NAGATAKI al $70^{\circ}$ Congreso Internacional de la Química (11) es digno de otras consideraciones.

En primer lugar, estudian la profundidad de neutralización - reducción de alcalinidaddel hormigón por el conocido procedimiento de la coloración o no coloración del mismo con fenolftaleína. En segundo lugar, observan a lo larga del tiempo la corrosión de ba. rras de acero embebidas en el hormigón a distintas profundidades —con distintos espesores de recubrimiento-. En tercer lugar, relacionan la "neutralización" del hormigón y la corrosión de las armaduras con la presencia de cenizas volantes en el hormigón.

Las observaciones de la profundidad de neutralización ponen de manifiesto que esta "neutralización" se produce en la parte externa - superficial o cortical-de las probetas, afectando tan sólo a un pequeño espesor de las mismas, de unos $2 \mathrm{~cm}$ o menos, y no se produce, en cambio, en la gran masa interior del hormigón. Esto es lo que, como es bien sabido, ocurre "también" por causa de la carbonatación, fenómeno que afecta a la superficie y a pequeños espesores, dependiendo de la porosidad — permeabilidad al aire- del hormigón y de las circunstancias ambientales - humedad relativa porcentual, contenido de $\mathrm{CO}_{2}$, temperatura, etc.- y de la probeta —estado higrométrico de la misma, estado o no de inmersión en agua, etc.-.

$\mathrm{Y}$ cabe pensar si la reducción de alcalinidad que los autores atribuyen a la "neutralización" por efecto puzolánico — parece que exclusivamente- de la ceniza volante, no será "también" debida, al menos en parte, a la carbonatación en ambientes de conservación interiores o de intemperie. Porque, de las trece referencias bibliográficas que los autores incluyen al final de su trabajo, y de las que sólo diez citan en el texto del mismo, únicamente tres: la 8 , la 9 y la 11 -́sta con la 12 y la 13 excluída del texto-, se refieren a la carbonatación. Y las dos citadas, 8 y 9, lo son por aspectos indirectos de la carbonatación, como son la influencia de la baja calidad del hormigón - pobre- y de la relación agua/cemento -alta-.

Ya que, si la reducción de alcalinidad fuese debida únicamente a la neutralización por la ceniza, ¿por qué tiene lugar sólo en la corteza y no en el interior de las probetas, siendo éstas macroscópicamente homogéneas? Es un punto que sin duda debe tener una explicación, pero que los autores no han dado.

Si interviene, aunque sólo sea en parte, la carbonatación $-\mathrm{y}$ es de pensar que lo hace en proporción no pequeña, si no de modo exclusivo-, el efecto de "neutralización" debería ser tanto mayor y más rápido y profundo cuanto más poroso, permeable y penetrable fuese el hormigón - es decir, cuanto peor fuese su calidad: más pobre en cemento y éste con clínker más flojo y con mayor proporción de ceniza, y con mayor relación agual/cemento-, tal y como, según los autores, sucede en la realidad. Esto sería inde- 
pendiente del hecho de que un menor contenido de clínker y un contenido mayor de ceniza en el cemento favoreciese la neutralización por esta última, pero por igual en toda la masa del hormigón y no solamente en la corteza del mismo.

Parece, por otra parte - aunque los autores no lo indican con absoluta claridad-, que el cemento como tal no tiene previamente incluida la ceniza, es decir, que ésta y el clínker no han sido molidos previa y conjuntamente en fábrica, sino que la ceniza ha sido añadida aparte, en la hormigonera. Porque, de ser realmente así, las cosas pueden cambiar mucho, según se argüirá más adelante.

Se indica en algunas referencias del trabajo que la variable predominante en la profundidad de "neutralización" es el factor agua/cemento, pero que las relaciones entre ambos son diferentes, dependiendo de la presencia o no de ceniza volante en el hormigón. Es más, en el propio trabajo se indica que dicha profundidad es algo menor en los hormigones que contienen ceniza que en los que no la contienen, incluso a la edad de diez años. La razón aducida para explicar este hecho es que la reacción puzolánica de la ceniza con la cal liberada en la hidratación da lugar a productos que densifican y colmatan la matriz de cemento, al propio tiempo que la acción dispersante - física- de la ceniza acelera la hidratación de la parte de clínker del mismo, con análogo resultado.

Es evidente que esta explicación parece querer apuntar más bien en el sentido de la carbonatación antes mencionada, pues presupone una acción "neutralizadora" de fuera hacia adentro, con el tope de una barrera. Porque, de no ser así, ¿por qué la neutralización de la ceniza tiene lugar sólo de la barrera hacia afuera -que es lo que detecta la prueba de la fenolftaleína- y no de la barrera hacia adentro? ise puede pensar que la acción puzolánica y "neutralizadora" de la ceniza es "topoquímica" en el sentido de que transcurre sólo en la corteza del hormigón y no en el interior de su masa? En tal caso, entre otras cosas, existirían heterogeneidades que se manifestarían en las resistencias de las probetas cilíndricas, siendo distintas las de las coronas cilíndricas exteriores que las de las almas cilíndricas interiores $\mathrm{y}$, por supuesto, mayores las primeras que las segundas.

Los propios autores caen en la cuenta de la posible y muy probable influencia importante de la carbonatación -y de la dependencia de ésta respecto de las condiciones higrométricas ambientales y del propio hormigón-, al comparar las profundidades de "neutralización" de probetas curadas en agua durante más o menos días y conservadas en interior o a la intemperie. Todo parece indicar que la profundidad de "neutralización" es mayor cuando las condiciones para la carbonatación son más propicias.

A mayor abundamiento en este mismo sentido, los autores hacen destacar el hecho de que en una región de su país en la que sumergieron probetas en agua de mar, éstas mostraron muy escasa "neutralización". ¿Y cómo, si ello no tiene por qué inhibir la reacción puzolánica neutralizadora de la ceniza? ¿No será que lo que se inhibe con la inmersión en agua de mar es precisamente la carbonatación, ya que, como es bien sabido, la carbonatación es prácticamente nula bajo agua? Sin embargo, en estas condiciones tuvo lugar la corrosión de los aceros, porque, con independencia de carbonatación o no, y de otro tipo de neutralización o no, lo que en tales circunstancias manda a los efectos es la salinidad -cloruros- del agua de mar, como bien apuntan los propios autores. Estos señalan que la corrosión se da incluso cuando todavía no ha progresado la "neutralización" - en el caso de hormigones no sumergidos habría que añadir también que cuando aún no ha tenido lugar la carbonatación-, y precisamente cuando el recubrimiento de los aceros es escaso y consistente en hormigón pobre, y en presencia de cloruros. Estando presentes éstos, y en tales condiciones, en efecto, con neutralización y/o carbonatación o sin ellas habrá siempre gran probabilidad de corrosión. 
Por otra parte, que las armaduras se corroan precisamente por el lado más próximo a la superficie del hormigón es natural, porque es adonde más pronto llegan los iones cloro y donde, en cualquier caso el hormigón puede estar más lixiviado, carbonatado y neutralizado, según las circunstancias, y donde, por consiguiente, es más fácil la destrucción de la capa de pasivación y más difícil su regeneración.

Finalmente los autores señalan que en las zonas centrales -internas- de las probetas, donde la "neutralizazión" no ha tenido lugar, se puede apreciar en fotografías de exploraciones con microscopio electrónico con enfoque en las cenizas volantes, que la reacción puzolánica entre la ceniza y la cal de hidrólisis se ha producido, y que sobre las partículas de ceniza se han formado cristales. Cabe pensar en cómo se compagina una reacción puzolánica de neutralización del $\mathrm{Ca}(\mathrm{OH})_{2}$ con la falta de neutralización, a no ser que por "neutralización" se entienda, en este punto del trabajo, carbonatación. Item más, se añade que en las partes neutralizadas de la corteza del hormigón no hay trazas de reacción en las superficies de las partículas de ceniza, lo cual es miás notorio en las condiciones de curado y conservación en interior que a la intemperie. $\mathrm{Y}$ cabe seguir pensando que ello puede ser debido a que la neutralización en este caso tiene muchas probabilidades de ser, al menos en gran parte, carbonatación.

En resumen y como constante del trabajo, se aprecia una falta de precisión entre la neutralización superficial o más o menos profunda, debida a la carbonatación y la generalizada a toda la masa de hormigón, debida a la reacción puzolánica de la ceniza.

Se confirma esto finalmente en la primera conclusión del trabajo, en la que se indica que la "neutralización" disminuye ligeramente cuando se añade ceniza volante al hormigón, lo cual en principio parece contradictorio, si por neutralización se entiende la reacción puzolánica entre ceniza y cal de hidrólisis. Fil resto de la primera conclusión y las restantes establecen relaciones entre la profundidad de la "neutralización" y: la calidad del hormigón, la relación agua/icemento, la resistencia a la compresión a 28 días, el período de curado y la conservación en ambiente interior o exterior. Y tan sólo al final de la conclusión cuarta y última se indica que existe una clara relación de causa a efecto entre el avanice de la "neutralización" al aire y la formación de herrumbre en las barras de acero. Lo mismo sería válido - y ello es cosa sabida - si en vez de "neutralización" en el sentido que parecen darle preferentemente los autores, se tratara claramente de carbonatación.

En vista de cuanto antecede, no parece muy claro ni seguro el poder atribuir el fenómeno de la corrosión de los aceros embebidos en hormigones que contienen cenizas volantes sólo a la reacción puzolánica de neutralización entre éstas y la cal liberada, y no, en cambio -al menos en parte-, a un proceso de neutralización por carbonatación.

En tal sentido es posible que todas o la mayoría, no ya de las cenizas volantes sólo, sino de las puzolanas en general, tuviese un comportamiento parecido. Pero, en todo caso, la cuestión habría que dilucidarla en cada caso por vía experimental directa pues, como se indicará al final, ni las puzolanas en general -incluídas las cenizas volantes-, ni las escorias siderúrgicas son, ni con mucho, materiales remotamente asimilables a especies químicas puras.

Lo que una puzolana cualquiera hace es, en primer lugar, sustituir a una buena parte de clínker en el cemento, con lo cual en la pasta de éste se forma menos cal de hidrólisis; y, en segundo lugar, fijar por reacción otra buena parte de ésta -aunque, en general, no toda-, con lo cual disminuye la reserva alcalina de la pasta (cantidad total de hidróxido cálcico libre), pero no necesariamente su alcalinidad o basicidad ( $\mathrm{pH}$ ). Por ello, mientras no desaparezca todo el hidróxido cálcico libre por neutralización (sea por car- 
bonatación y/o sea por reacción puzolánica) y baje el $\mathrm{pH}-\mathrm{y} / \mathrm{o}$ intervengan cloruros-, en igualdad de circunstancias no habrá más peligro de corrosión de armaduras, generalizada en un caso y localizada en otro, en un hormigón de cemento puzolánico -con puzolana natural o con cenizas volantes- que en un hormigón con cemento portland. Pero en el caso de que el hormigón corra peligro de neutralización total en un medio dado, o por carbonatación o por reacción puzolánica, o de ser afectado él y las armaduras por la presencia o penetración de iones despasivantes, es evidente que el cemento portland puede proteger más y mejor -durante más tiempo- a las armaduras que cualquier cemento puzolánico, cualquiera que sea la puzolana que contenga, a igualdad de las demás circunstancias, por la mayor reserva alcalina del primero. Por supuesto que quedan deliberadamente al margen en esta ocasión, los casos específicos de corrosión, como la que se da bajo tensión, o la que inducen los sulfuros, circunstancialmente presentes en algunas adiciones.

Hay que tener también presente que es de todo punto presumible que la mayor o menor protección que unos u otros cementos puedan conferir "al acero" dependa del tipo y naturaleza de éste, y que no parece lícito hablar de "acero" en un término genérico, sino que es necesario especificar de qué acero se trata en cada caso, pues un mismo cemento puede proteger más o menos a unos que a otros. Y, por supuesto, que esta mayor o menor protécción podrá depender también de las condiciones y circunstancias del propio hormigón, como pueda ser su mayor o menor facilidad para la carbonatación y la velocidad y profundidad que ésta alcance, la presencia inical de cloruros en él o la penetración de éstos a posteriori, la existencia de sulfuros en el cemento aportados por algunas adiciones, y de tantas variables y parámetros, generalmente no todos siempre o bien especificados, de los cuales se sabe que influyen, en signo y magnitud, en la pasivación y protección que unos $u$ otros cementos proporcionan a unos $u$ otros aceros.

Una cuestión colateral, pero muy importante, es la relativa a una misma ceniza volante incorporada, bien al clínker para formar un cemento puzolánico, o bien al hormigón en la hormigonera. Aún siendo la proporción de adición igual en ambos casos, los resultados pueden ser muy diferentes. En efecto, según sea cada ceniza en particular -y ésta es otra faceta digna de ser tenida en cuenta-, puede contener una proporción mayor o menor de carbón y de cenosferas. El carbón puede actuar, por sus propiedades adsorbentes, como neutralizante de la acción de determinados aditivos para hormigón; las cenosferas pueden actuar en éste como un fluidificante, de forma muy parecida a como actúan los agentes inclusores de aire, y pueden también suplantar al árido más fino o incrementar las fracciones más finas de éste, de tamaño equivalente al suyo.

Ambas acciones pueden ejercer determinados efectos de una magnitud y signo dados, en cuanto a ciertas características y comportamientos reológicos del hormigón (o relacionados con ellos), como, por ejemplo, la exigencia y retención $\longrightarrow$ rechazo- de agua para una plasticidad dada, la segregación, la exudación (rezumado o "sangrado"), la sedimentación, etc. Estos efectos se manifiestan -en pro o en contra de lo requerido y deseado-, cuando las cenizas se añaden en la hormigonera, juntamente y al mismo tiempo que los restantes componentes del hormigón.

Pero cuando las cenizas se añaden al clínker en el molino de cemento, y se mezclan y muelen conjuntamente con él, la mayor parte de las cenosferas, si no todas ellas, se rompen en la molturación, y los efectos anteriores - para bien o para mal, según los casos-, quedan eliminados o muy atenuados.

Por consiguiente, es de esperar que, en general, los resultados de añadir la misma cantidad de una determinada ceniza volante al hormigón, sea en la propia hormigonera, o sea al clínker en el molino de cemento en fábrica, pueden ser muy diferentes en los as- 
pectos reológicos señalados $\mathrm{y}$, por qué no, en los más o menos directamente derivados de ellos, como pueden ser, entre otros, el de la mayor o menor facilidad para la corrosión de las armaduras.

Es evidente que los mejores efectos y, sobre todo, los más regulares y menos sorprendentes en cuanto a uniformidad y regularidad del hormigón, y en cuanto a la mejor vigilancia y control de éste, se puedan obtener mediante el uso de cementos con cenizas volantes, ya preparados en las clásicas fábricas de cemento.

Y en tal sentido ya se señaló en el Congreso de París (12) que para cementos con contenidos de cenizas volantes hasta un 15 por ciento, la molienda conjunta es óptima, mientras que para proporciones mayores es mejor la separada; y que un reparto conveniente de la energía total de molienda entre el clínker y el yeso por un lado y la ceniza volante por otro - debe entenderse un acoplamiento de las finuras de los materiales para conseguir una curva granulométrica óptima del conjunto-, puede proporcionar un incremento considerable de las resistencias a corto plazo de los cementos con cenizas. A esto hay que añadir que no todos los cementos puzolánicos en general requieren mayor cantidad de agua que los portland para una consistencia de hormigón dada. Entre los que puedén requerir cantidades incluso menores suelen estar los cementos con cenizas volantes; pero de todas formas el incremento en la cantidad de agua para alcanzar una consistencia dada es, en su caso, insignificante (7) (8).

Los autores del trabajo japonés comentado no indican explícitamente si las cenizas objeto de su estudio iban ya incluidas en los cementos que utilizaron, o si fueron incorporadas aparte, al hormigón. Pero por algo de lo ya indicado antes y por el título del trabajo: "Long term experiments on the neutralisation of concrete mixed with fly ash and the corrosion of reinforcement", así como por el texto relativo a la serie I del programa de ensayos (página IV-31 del trabajo), en el que se dice que "las cenizas volantes fueron suministradas por seis fabricantes, mientras que el cemento fue el mismo $\longrightarrow$, mejor, los cementos fueron los mismos (redacción inglesa defectuosa) la dosificación a base de "unit cement- fly ash content", parece poderse deducir con fundamento que las cenizas no formaban parte de los cementos, sino que se añadieron a los homigones en el momento de ser amasados. A mayor abundamiento en este sentido, los autores señalan que utilizaron "un cemento normal" y un "cemento de calor moderado". Cabe, por lo tanto, pensar en virtud de lo anterior en cuáles hubieran sido los resultados obtenidos si con los mismos cementos y cenizas, en las mismas proporciones relativas y icon las mismas dosificaciones "globales" en los hormigones, las cenizas hubieran estado previamente contenidas en los cementos. Una vez más, esta confirmación experimental directa hubiera sido de gran valor.

Un último aspecto de la mayor importancia es el de la individualidad de los materiales de adición: puzolanas, cenizas volantes y escorias, en el sentido de que no es lícito generalizar y extrapolar a todas las puzolanas, o a todas las cenizas volantes, o a todas las escorias, el comportamiento de algunas determinadas. Estos materiales son de tal naturaleza que su tratamiento genérico es muchas veces comprometido, y vale más tratarlos específicamente. $\mathrm{Y}$ mucho más cuando, como el caso de las cenizas volantes se incluyen a veces entre ellas las que no lo son; o cuando rocas volcánicas, por el simple hecho de serlo y sin poseer —o poseyendo apenas - carácter puzolánico, se consideran como verdaderas puzolanas; o cuando las escorias siderúrgicas - por no citar a las que por formarse en otras metalurgias no férreas no lo sean-, son poco básicas, o no son debidamente granuladas, y se admiten como tales.

Más aún: no todas las cenizas, aún siendo auténticamente volantes, son siempre suficientemente activas desde un punto de vista puzolánico. Lo serán más o menos en fun- 
ción de su composición química, de su naturaleza más o menos vítrea o cristalina, de su grado de dispersión o finura, etc., pero también de la temperatura a la que se hayan formado y del enfriamiento que hayan sufrido. Es bien sabido que cuando se activan térmicamente arcillas de composición y naturaleza idóneas para obtener puzolanas artificiaies, hay una temperatura óptima de activación que grosso modo se sitúa según los materiales de partida, entre los $700-750^{\circ} \mathrm{C}$ y los $800-850^{\circ} \mathrm{C}$. Por debajo de la correspondiente temperatura en estos márgenes no hay activación suficiente, y por encima hay desactivación de la previamente induicida. Pues bien, con las cenizas volantes que, en definitiva, también son materiales térmicamente activados, sucede algo parecido: las cenizas formadas a temperaturas del orden de $1.000^{\circ} \mathrm{C}$, por ejemplo, son materiales que, como los óxidos "calcinados a muerte", presentan escasa reactividad; mientras que las formadas a temperaturas óptimas o próximas a ellas, muestran una actividad y una acción puzolánica mucho mayores. La velocidad de enfriamiento de las cenizas, como en el caso del clínker y de las escorias, influye en la proporción de fase vítrea, siempre potencialmente más activa que las correspondientes o equivalentes fases cristalinas.

De hecho, en el propio Congrẹso de París quedó bien de manifiesto (7) (8) una serie de hechos tales como los siguientes, que permiten puntualizar mucho más acerca de las cenizas volantes entre sí y en relación con otras puzolanas naturales, a saber:

i) que la composición química global de las cenizas de carbones usualmente quemados en las centrales termoeléctricas es, en general, menos variable que la de las puzolanas naturales;

ii) que las diferencias de composición entre puzolanas naturales y artificiales no son mayores que las que se aprecian dentro de cada grupo, como, por ejemplo, entre puzolanas vítreas y zeolíticas;

iii) que tal vez el grupo más homogéneo sea el de las cenizas volantes de igual origen, génesis y composiciòn;

iv) que, en cambio, la composición y la constitución de las cenizas volantes varía apreciablemente según el tamaño de las fracciones granulométricas, pues aunque la composición mineralógica sea cualitativamente la misma, puede variar la cristalinidad, de manera que en los finos haya mayor cantidad de fases cristalinas, mientras que en los gruesos abunde más el vidrio;

v) que la composición y constitución de las cenizas volantes de lignitos y de carbones sub-bituminosos son diferentes de las de los carbones comunes, y mucho más variables, tanto en el aspecto químico y mineralógico como en cuanto al contenido y la naturaleza de la fase vítrea. Las cenizas de los primeros son más básicas y ricas en cal total y libre, así como en dos de los cinco tipos de vidrio que, en general, se han encontrado en las cenizas volantes; estas cenizas pueden tener, por lo tanto, actividad hidráulica propia. Pese a su mayor contenido de cal libre, si éste no excede del 15 por ciento no hay peligro de expansión, dado su pequeño tamaño de grano, su gran dispersión y su rápida y total hidratación;

vi) que en las cenizas de carbón granuladas (URSS) cambia la proporción y la composición de la fase vítrea en función de la relación (cal + magnesia/sílice + alúmina) -más o menos análogamente a lo que sucede con el criterio de la hidraulicidad de las escorias básicas granuladas de horno alto-, de tal modo que si la citada relación excede de 1 las cenizas tienden a la cristalinidad, perdiendo actividad a pesar de la mayor hidraulicidad que podría esperarse de su composición. Y sin embargo, con composiciones análogas a las del clínker la mayor cristalinidad puede resultar 
beneficiosa, por cuanto que induce a la formación de alita y belita con poder hidráulico propio, lo mismo que sucede con las cenizas más básicas y ricas en cal de los lignitos y carbones sub-bituminosos;

vii) que las cenizas volantes pueden contener carbón en distintas proporciones, lo cual es un inconveniente en multitud de aspectos, entre ellos el de la adsorción de posibles aditivos para hormigón, inhibiendo la acción de éstos;

viii) que asimismo pueden contener cenosferas en proporciones diferentes, las cuales confieren a las cenizas una menor densidad aparente, por lo demás variable;

ix) que en las pastas, morteros y hormigones con cenizas volantes no se fija toda la cal de hidrólisis por reacción puzolánica, de manera que queda siempre la suficiente en cantidad apreciable para mantener un $\mathrm{pH}$ del orden de 12,5 o mayor, el cual confiere una buena protección a las armaduras; y esto aunque la puzolana -en el caso de las puzolanas naturales-, sea muy activa, rica en sílice y pobre en cal;

x) que, por otra parte, a igual trabajabilidad del hormigón la profundidad de neutralización en éste - debe entenderse que por carbonatación- es tanto menor cuanto mayor es la dosificación de cemento y tanto mayor cuanto mayor es el contenido de ceniza, ya que la reacción puzolánica lo que hace es, como se ha indicado antes, fijar cal reduciendo la reserva alcalina, y en tal sentido, acelerar la neutralización por carbonatación.

Todo ello lleva obligadamente a esta consecuencia final: aparte de los comentarios críticos en cuanto a fondo y forma del trabajo de referencia (11) hechos en lo que precede, las conclusiones de sus autores, tanto las generales como la única relativa a la corrosión de armaduras, con todo su valor particular atribuible al caso estudiado, no se pueden extender ni generalizar de ninguna manera, no ya a otros materiales puzolánicos naturales o artificiales en bloque, sino ni siquiera a otras cenizas volantes, aún similares en origen y formación a las utilizadas por los autores en su trabajo, e incluso en la forma en que éstos lo hacen.

En otro orden de ideas, conviene hacer hincapié en la conclusión a que llega VIRELLA en su referencia al Tema IV sobre PUZOLANAS Y CENIZAS VOLANTES (5) del 7. CONGRESO INTERNACIONAL DE LA QUIMICA DE LOS CEMENTOS (París, Julio 1980): es absolutamente cierto que algunos investigadores de entre los más "puros" y que tienen a su disposición laboratorios y equipos modernos, complejos y costosos, corren a veces el riesgo de sentirse proclives a "abusar" -0 si se prefiere a exprimir en demasía las posibilidades- de dichos medios, ante la facilidad de obtener rápidamente resultados publicables, podría decirse que "en serie", aunque no siempre "en serio". Y cuando esto sucede, y porque esto sucede, muchas veces se pierden de vista los verdaderos y cotidianos problemas, pedestres si se quiere, pero reales y acuciantes, de quienes fabrican y utilizan los materiales objeto de los estudios más finos. Problemas que, por otra parte, con la atención debida se resolverían con medios quizás también pedestres; pero, eso sí, con la atención y el conocimiento adecuados, porque no todo es cuestión de medios. Del mejor investigador experimental se ha dicho que es aquél "capaz de aserrar con una lima y limar con una sierra".

Pero no es menos cierto que para poder llegar a dar una información científica y veraz del comportamiento de las adiciones a los cementos y de los cementos con adiciones, es preciso hacer ciencia, la ciencia de estos materiales, y técnica - la de los mismos-, tanto "in vitro" como "in vivo". Lo que ocurre es que el logro del conocimiento necesario, a escala de generalización, es árduo y lento, discutiblemente posible y escasamente proba- 
ble, pues en cualquiera de los grupos o géneros de materiales de adición y de cementos derivados de ellos no hay dos especies iguales.

Se intenta dar a dichos grupos o géneros el mismo tratamiento y consideración que si fueran especies químicas puras y únicas, cuando cada individuo de cada familia es diferente y a veces muy distinto de sus congéneres. De ahí la jmposibilidad de extrapolar y de generalizar, del gran riesgo de error que comporta el hacerlo, y de la necesidad de salvaguandar unas de otras las distintas individualidades de los materiales, respecto de su naturaleza, propiedades y comportamientos. Lo cual no descarta, antes bien aconseja, el estudio y la investigación de cada uno, siempre que sea preciso resolver un problema específico, pero de interés general.

\section{RE F R E N C I A S}

(1) Virella Bloda, A.: “El 7. Congreso Internacional de la Química de los Cementos". Paris, 1980. Cemento-Hormigón, LI (561) AGO, págs. 643-652 (1980).

(2) Virella Bloda, A.: Ibid., LI (562) SEP, págs. 771-794 (1980).

(3) Virella BlodA, A.: Ibid., LI (564) NOV. págs. 956-973 (1980).

(4) Virella Bloda, A.: Ibid., LI (565) DIC. págs. 1.039-1.057 (1980).

(5) Virella Bloda, A.: Ibid., LII (570) MAY. págs. 436-443 (1981).

(6) Massazza, F.: "Structure of puzzolana and fly-ash and the hydration of pozzolanic and fly-ash cements". Proceedings of the 7 International Congress on the Chemistry of Cements", Paris, Julio 1980, Tema IV: Puzolanas y Cenizas Volantes, General Report, Vol. 3, págs. 85-90 (1981).

(7) Mesa Redonda del Tema IV: Puzolanas y Cenizas Volantes, Proceedings of the 7 International Congress on the Chemistry of Cements. París, Julio 1980, Vol. 3, págs. 91-96 (1981).

(8) Calleja, J.: "Presencia y actuación española en la 30 Reunión de Técnicos de la Industria del Cemento del Brasil: "Cementos con adiciones". Materiales de Construcción (IETCC), núm. 175 JULr AGO-SEP, págs. 51-69 (1979).

(9) Garcta de Paredes, P.: "Inaltérabilité des liants face à l'attaque des sulfates. Comparaison des méthodes pour son appreciation". Cahiers de Recherche (IETCC), núms. 13 y 14 (1967).

(10) Calleja, J. y Garcia de Paredes, P.: "On the methods to study the durability of hydraulic cements". Proceedings RILEM Symposium on Concrete Durability, Praga, 1969. Cahiers de Recherche (IETCC), núm. 21 (1969).

(11) Tsukayama, R. ABE, H. y Nagataki, S.: "Long term experiments on the neutralisation of concrete mixed with fly-ash and the corrosion of reinforcement". Proceedings of the 7 International Congress on the Chemistry of Cements, París, Julio 1980, Vol. 3. Tema IV: Puzolanas y Cenizas Volantes, págs. IV-30 a IV-35 (1981).

(12) Alsted Nielsen, H. C.: "Preparation on fly ash cements". Proceedings of the 7 International Congress on the Chemistry of Cements, París, Julio 1980. Tema IV: Puzolanas y Cenizas Volantes, Vol. 3, págs. IV-72 a IV-77 (1981). 